TIMP-1 in asthma

\section{TIMP-1 in asthma: guilty by association}

S R Johnson

\section{A novel TIMP-1 polymorphism is associated with asthma in women}

$\mathrm{O}$ ver the last few years there has been increasing interest in the matrix metalloproteinases (MMPs) in asthma. The MMPs are a family of over 20 zinc dependent endopeptidases with a range of substrate specificities. Although originally classified into gelatinases, stromolysins, collagenases, and matrilysins by their ability to cleave extracellular matrix components, it is now clear that MMPs have an increasing range of other functions. Of potential relevance to asthma is the release and activation of growth and angiogenic factors including transforming growth factor $\beta$ (TGF $\beta)^{1}$ and vascular endothelial growth factor (VEGF), ${ }^{2}$ apoptosis by release of Fas ligand, ${ }^{3}$ and activation of cell surface receptors-collectively resulting in effects on cell differentiation, survival, proliferation, and migration. ${ }^{4}$ MMP activity is tightly regulated at several levels. Gene transcription is enhanced by growth factors, cytokines and adhesion molecules and downregulated by TGF $\beta$ and corticosteroids. ${ }^{5}$ MMPs are secreted as zymogens which require activation by proteolytic cleavage either at the cell surface or in solution by other proteases including MMPs. ${ }^{5}$ Once activated, natural inhibitors including tissue inhibitors of metalloproteinases (TIMPs) bind different MMPs with varying specificities in a $1: 1$ ratio to inhibit proteolytic activity. ${ }^{6}$ There are four TIMP proteins which, in addition to their antiprotease actions, also have other functions-with TIMP-1 modulating proliferation, apoptosis, and angiogenesis in various tumour cell types. ${ }^{78}$

\section{MMPs AND TIMPs IN ASTHMA}

It has been suggested that, in asthma, MMPs contribute to altered extracellular matrix turnover, influx of proinflammatory cells, epithelial repair, and angiogenesis. ' In animal models of asthma, allergen challenge in MMP-9 and MMP-2 knockout mice results in reduced numbers of inflammatory cells in the airways compared with wild type mice due to deranged chemokine gradients. ${ }^{10}$ The role of MMPs in asthma is complex as, paradoxically, in MMP-2 knockout mice, despite a reduction in airway inflammatory cells, there is an increase in parenchymal inflammatory cells due to impaired cell egress. ${ }^{11}$ These and other data suggest specific roles for different MMPs, despite apparently equivalent substrate specificities. This level of complexity, brought about by differential activity of individual proteases both spatially and temporally within the lung, may explain the lack of efficacy of broad spectrum MMP inhibitors in models of asthma. In human asthma most studies have measured MMP and TIMP protein levels and estimated activity by the presence of the active protein or by the MMP/TIMP ratio. This approach may not truly represent overall protease activity as other MMPs and MMP inhibitors may be present (including TIMPs, $\alpha$-macroglobulin, and thrombospondins $s^{7}$ ) which are undetected. ${ }^{12}$ These reservations notwithstanding, studies suggest that MMP-9 is the predominant airway MMP and is increased in the sputum ${ }^{13}$ and bronchoalveolar lavage fluid ${ }^{14}$ of patients with asthma and further increased during exacerbations. ${ }^{15}$ The precise relationship between MMP-9 and TIMP-1 (the major inhibitor of MMP-9) levels in asthma is still being evaluated. One study has shown that the MMP-9/TIMP-1 ratio and specific MMP-9 activity is increased in asthma, ${ }^{16}$ while others have shown that a reduction in the MMP-9/TIMP ratio was associated with worsening airflow obstruction in asthma and increased airway wall thickness, suggesting that lower MMP-9/TIMP-1 ratios may be associated with a profibrotic environment with reduced extracellular matrix turnover leading to airway remodelling. ${ }^{17}$ The recent association of ADAM 33 (A Disintegrin And Metalloprotease) with asthma and bronchial hyperresponsiveness $^{18}$ has further turned the focus of asthma research toward the MMPs and related proteases. The association of ADAM 33 with asthma is made all the more intriguing by the findings that most ADAM 33 transcripts expressed in fibroblasts do not contain the metalloproteinase domain, which suggests that non-proteolytic activities of the MMP/TIMP proteins may also be of relevance in asthma. ${ }^{19}$

\section{ASSOCIATION OF A NOVEL TIMP-1 POLYMORPHISM WITH ASTHMA IN WOMEN}

It is timely that, in this issue of Thorax, Lose et $a l^{20}$ add to the evidence for involvement of MMPs and TIMPs in asthma with an association study of MMP-9 and TIMP-1 polymorphisms in 543 patients with asthma. Although polymorphisms in MMP-9 were not associated with asthma in this population, a novel TIMP-1 polymorphism in the MMP-9 binding domain was associated with asthma, but not atopy, in women. This provides further evidence that TIMP-1, and possibly the MMP-9/ TIMP-1 axis, are involved in the development of asthma rather than merely being deranged in the disease. The 536C $>\mathrm{T}$ polymorphism in exon 6 of TIMP-1 does not result in an amino acid change but is predicted to affect RNA splicing, possibly leading to the expression of different TIMP-1 splice variants. What is not clear is how this polymorphism affects an individual's susceptibility to asthma. As the polymorphism is present in the MMP-9 binding site, it is tempting to speculate that TIMP-1 inhibitory activity against MMP-9 is impaired, possibly allowing enhanced airway inflammatory cell recruitment in response to allergen. The investigators did not examine the level of TIMP-1 in the airways of their patients, the presence of TIMP-1 splice variants, or the function of this polymorphism. Genetic association studies of this type are frequently performed in asthma and have identified a large number of apparently linked gene loci which have not been reproduced by other groups. The strengths of the current study, however, are that the investigators have used a large population of patients with a rigorously characterised asthma phenotype and have studied a set of polymorphisms in biologically relevant genes known to be linked to other diseases categorised by deranged MMP/TIMP activity including atherosclerosis $^{21}$ and emphysema. ${ }^{22}$ Furthermore, the relationship between the 536C $>\mathrm{T}$ polymorphism and asthma in women is also supported by a TIMP-1 haplotype association with asthma. However, it remains essential to confirm these findings in other asthma populations and to study the function of the newly identified polymorphism with regard to both its anti-MMP activity compared with the wild type protein and non-antiprotease TIMP functions including cellular growth and apoptosis.

With this study, Lose et al have implicated TIMP-1 as a potential player 
in the development of the asthmatic phenotype. It is now essential that we look beyond MMP/TIMP levels toward specific protease activity and non-protease functions of these molecules to understand if selectively affecting their function could be an effective treatment for asthma.

Thorax 2005;60:617-618.

doi: 10.1136/thx.2004.036475

Correspondence to: $\operatorname{Dr}$ S R Johnson, Division of Therapeutics and Molecular Medicine, University Hospital, Queens Medical Centre, Nottingham NG7 2UH, UK; simon.johnson@ nottingham.ac.uk

The author's work is supported by Asthma UK.

The author declares no conflict of interest.

\section{REFERENCES}

1 Yu Q, Stamenkovic I. Cell surface-localized matrix metalloproteinase-9 proteolytically activates TGF$\beta$ and promotes tumor invasion and angiogenesis. Genes Devel 2000;14:163-76.

2 Engsig MT, Chen Q-J, Vu TH, et al. Matrix metalloproteinase 9 and vascular endothelial growth factor are essential for osteoclast recruitment into developing long bones. J Cell Biol 2000;151:879-90.

3 Kayagaki N, Kawasaki A, Ebata T, et al. Metalloproteinase-mediated release of human Fas ligand. J Exp Med 1995;182:1777-83.
4 Werb Z. ECM and cell surface proteolysis: regulating cellular ecology. Cell 1997;91:439-42.

5 Nagase H, Woessner JF Jr. Matrix metalloproteinases. J Biol Chem 1999;274:21491-4.

6 Stamenkovic I. Extracellular matrix remodelling: the role of matrix metalloproteinases. J Pathol 2003;200:448-64.

7 Baker AH, Edwards DR, Murphy G. Metalloproteinase inhibitors: biological actions and therapeutic opportunities. J Cell Sci 2002;115:3719-27.

8 Martin DC, Fowlkes JL, Babic B, et al. Insulin-like growth factor II signaling in neoplastic proliferation is blocked by transgenic expression of the metalloproteinase inhibitor TIMP-1. J Cell Biol 1999:146:881-92.

9 Kelly EA, Jarjour NN. Role of matrix metalloproteinases in asthma. Curr Opin Pulm Med 2003;9:28-33.

10 Corry DB, Kiss A, Song L-Z, et al. Overlapping and independent contributions of MMP2 and MMP9 to lung allergic inflammatory cell egression through decreased CC chemokines. FASEB J 2004; 18:995-7

11 Corry DB, Rishi K, Kanellis J, et al. Decreased allergic lung inflammatory cell egression and increased susceptibility to asphyxiation in MMP2deficiency. Nature Immunol 2002;3:347-53.

12 Elshaw SR, Henderson N, Knox AJ, et al. Matrix metalloproteinase expression and activity in human airway smooth muscle cells. Br JPharmacol 2004; 142:1318-24.

13 Vignola AM, Riccobono L, Mirabella A, et al. Sputum metalloproteinase-9/tissue inhibitor of metalloproteinase-1 ratio correlates with airflow obstruction in asthma and chronic bronchitis. Am J Respir Crit Care Med 1998;158:1945-50.
14 Mautino G, Oliver N, Chanez P, et al. Increased release of matrix metalloproteinase- 9 in bronchoalveolar lavage fluid and by alveolar macrophages of asthmatics. Am J Respir Cell Mol Biol 1997; 17:583-91.

15 Oshita Y, Koga T, Kamimura T, et al. Increased circulating $92 \mathrm{kDa}$ matrix metalloproteinase (MMP-9) activity in exacerbations of asthma. Thorax 2003;58:757-60.

16 Yao PM, Lemjabbar H, D'Ortho MP, et al. Balance between MMP-9 and TIMP-1 expressed by human bronchial epithelial cells: relevance to asthma. Ann NY Acad Sci 1999;878:512-4.

17 Matsumoto $\mathrm{H}$, Niimi A, Takemura $M$, et al. Relationship of airway wall thickening to an imbalance between matrix metalloproteinase-9 and its inhibitor in asthma. Thorax 2005:60:277-81.

18 Van Eerdewegh P, Little RD, Dupuis J, et al. Association of the ADAM33 gene with asthma and bronchial hyperresponsiveness. Nature 2002;418:426-30.

19 Powell RM, Wicks J, Holloway JW, et al. The splicing and fate of ADAM33 transcripts in primary human airways fibroblasts. Am J Respir Cell Mol Biol 2004;31:13-21.

20 Lose F, Thompson PJ, Duffy D, et al. A novel tissue inhibitor of metalloproteinase-1 (TIMP-1) polymorphism associated with asthma in Australian women. Thorax 2005;60:623-8

21 Zhang B, Ye S, Herrmann S-M, et al. Functional polymorphism in the regulatory region of gelatinase $B$ gene in relation to severity of coronary atherosclerosis. Circulation 1999;99:1788-94.

22 Minematsu N, Nakamura $\mathrm{H}$, Tateno $\mathrm{H}$, et al. Genetic polymorphism in matrix metalloproteinase-9 and pulmonary emphysema. Biochem Biophys Res Com 2001;289:116-9.

\section{Impact of changes in the International Olympic Committee Medical Commission criteria for asthma}

\section{L-P Boulet}

\section{Objective measurements of variable airflow obstruction in athletes} using inhaled bronchodilators are needed if the non-indicated use of asthma drugs is to be prevented

$\Lambda$ large number of Olympic athletes have asthma, and intense exercise has the potential to alter their sports performances in inducing troublesome respiratory symptoms. ${ }^{12}$ The prevalence of asthma in Olympic athletes has been reported to be between $9 \%$ and $55 \% .{ }^{1-5}$ It is particularly high in winter sports athletes and in swimmers, and its prevalence has been reported to be increasing. Furthermore, high level training is thought to contribute to the development of airway hyperresponsiveness and symptomatic asthma. ${ }^{23}$

Although most current asthma medications, including the frequently used inhaled short acting $\beta_{2}$ agonists, do not seem to have performance enhancing effects when used at doses required to prevent or treat exerciseinduced bronchoconstriction, their use has been regulated. ${ }^{6-9}$ To ensure that they are used for an appropriate diagnosis, the International Olympic Committee-Medical Commission (IOCMC) has established criteria for a positive diagnosis of asthma. It includes a significant bronchodilator response, or a positive bronchial provocation challenge, a fall in forced expiratory volume in 1 second of at least $10 \%$ from pre-challenge measures being required for exercise or eucapnic voluntary hyperpnoea. ${ }^{10}$
In this issue of Thorax, Dickinson et al looked at the influence of these recently established criteria on the prevalence of asthma in the British Olympic Team participating to the 2004 Olympic Games in comparison to the year $2000 .{ }^{4}$ In 2000 the diagnosis was established by analysing the pre-Olympic medical forms while, in 2004, the diagnosis required a positive bronchodilator or bronchoprovocation test. A similar prevalence of asthma was found $(21.2 \%$ in 2000 and $20.7 \%$ in 2004); however, seven athletes without a previous diagnosis of asthma tested positive and $21 \%$ (13 of 62) previously diagnosed with asthma did not meet the IOC-MC criteria for the disease, suggesting that they may have been taking a medication without indication. The new criteria therefore did not change the overall prevalence of diagnosed asthma, but a significant number of athletes with a previous diagnosis of asthma were no more recognised as such.

We should, however, be careful in the interpretation of these data, as athletes may have symptoms related to underlying lower or upper airway inflammation or to the intensity of respiratory heat exchange during exercise, particularly as a cough, without obvious airway obstruction. ${ }^{11}$ These symptoms could result from a process that does not 
necessarily translate into changes in airway function; they may simply be an effect of sensory nerve ending stimulation from intense hyperventilation, particularly when exposed to cold air in winter sports athletes or to environmental pollutants such as chlorine derivatives in swimmers. We may question if we should call these features "asthma", but they may respond to bronchial anti-inflammatory agents. These respiratory symptoms may also be due to a cause other than lower airway stimulation/inflammation and require another form of treatment. This may, at least in part, explain why "asthma like" symptoms in athletes may be refractory to asthma medications. ${ }^{12}$

Furthermore, the absence of variable airway obstruction at the time of testing may be due to its variability over time, particularly if there is intercurrent allergen exposure in atopic subjects. ${ }^{13}$ If exposed to allergens, airway responsiveness may increase and then return to normal in the presence of mild asthma. So, the timing of the tests is crucial. In the study by Dickinson et al we have no information on the atopic status and allergen exposure of the various athletes, so it is difficult to determine if this could explain the changes observed. Other environmental factors may also influence the results. In this regard, Hemingson et $^{1 l^{14}}$ have suggested that airway hyperresponsiveness could increase when training during the winter in non-atopic athletes, possibly due to the effect of cold air on airways.

There is, nevertheless, a significant group of individuals both in the general population and in athletes who have asymptomatic airway hyperresponsiveness. ${ }^{15}$ Rundell et al ${ }^{16}$ compared symptom based diagnosis with a diagnosis following exercise challenge in elite winter athletes; of the $26 \%$ of participants who were positive for exercise induced bronchoconstriction, only 39\% reported more than one symptom on the questionnaire. There may therefore be a relatively frequent underreporting of asthma symptoms in athletes. This may reflect truly asymptomatic airway hyperresponsiveness or be associated with mild asthma with underreporting or non-recognition of symptoms.

Otherwise, overdiagnosis of asthma is common in the general population and this may also apply to athletes. ${ }^{517}$ It is often considered to be due to a lack of objective measures of airway function and to result in unnecessary or inappropriate care. Questionnaires without objective measures may lead to both false negative and false positive diagnoses of asthma and be of limited usefulness in detecting airway hyperresponsiveness. ${ }^{18}$ A cough may be due to an upper airway disease (allergic or not) or to gastro-oesophageal reflux, and other conditions may mimic asthma. LindenSmith et al ${ }^{17}$ studied a self-referred sample of physician labelled adult asthmatics recruited in the community; $41 \%$ had no evidence of reversible airflow obstruction and had a negative methacholine challenge test result.

All these observations support the need for objective measures of airway function, in keeping with the IOC-MC recommendations, but also stress the need to study further the influence of intense training on respiratory symptoms and their underlying mechanisms, particularly in relation to airway inflammation and function. The IOC-MC recommendations are in keeping with national and international asthma consensus guidelines, these last recommending the demonstration of variable airway obstruction-either from bronchodilator response, variation in expiratory flows, or an increase in the airway response to direct or indirect stimuli-to establish a diagnosis of asthma in a patient with compatible symptoms. ${ }^{1920}$ Anderson et al analysed applications to the 2002 Winter Olympics and found that it was feasible to request objective evidence to justify the use of $\beta_{2}$ agonists on medical grounds of asthma or exercise induced asthma, with 130 of 165 applications being approved.

Another recent publication is of interest with regard to the potential overuse of bronchodilators in Olympic athletes. In view of the progressive increase in notifications of the use of $\beta_{2}$ agonists since the early 1980s, ${ }^{9}$ Alaranta et $a^{21}$ performed a cross sectional questionnaire survey in Finnish Olympic athletes in 2002. The use of any asthma medication was reported by $9.6 \%$ of athletes and by $4.2 \%$ of control non-athletes (7.4\% and $3.0 \%$, respectively, for inhaled $\beta_{2}$ agonists). None of the athletes used asthma medication without a physician diagnosis. This study indicates that the frequency of use of asthma medication is lower than the occurrence of physician diagnosed asthma in these Olympic athletes, suggesting that inhaled $\beta_{2}$ agonists are not overused. Nevertheless, as previously mentioned, physician diagnosed asthma is not always based on objective evidence.

So, despite the obvious difficulties in interpreting respiratory symptoms in athletes, objective measurements of variable airflow obstruction in athletes using inhaled bronchodilators are needed if the non-indicated use of asthma drugs is to be prevented. The study by Dickinson et al brings relevant information on the consequences of using specific criteria to diagnose asthma in elite athletes. Overall the influence is limited, but the change in "asthma" status is not uncommon. There is a need to explore further the relationships between high level exercise and asthma and the various consequences of intense training in athletes, including non-invasive measures of airway inflammation. Not only should this help to establish an appropriate diagnosis, but it could contribute to a better understanding of the mechanisms by which intense exercise could induce respiratory symptoms and to determine what is the optimal treatment for these problems.

Thorax 2005;60:618-620.

doi: $10.1136 /$ thx. 2005.040840

Correspondence to: Dr L-P Boulet, Institut de cardiologie et de pneumologie de l'Université Laval, Hôpital Laval, 2725 Chemin Sainte-Foy, Quebec City QC, Canada GIV 4G5; Ipboulet@med.ulaval.ca

\section{REFERENCES}

1 Helenius I, Haahtela T. Allergy and asthma in elite summer sport athletes. J Allergy Clin Immunol 2000; 106:444-52

2 Langdeau JB, Boulet LP. Prevalence and mechanisms of development of asthma and airway hyperresponsiveness in athletes. Sports Med 2001;31:601-16.

3 Langdeau JB, Turcotte H, Bowie DM, et al. Airway hyperresponsiveness in elite athletes. Am J Respir Crit Care Med 2000;161:1479-84.

4 Dickinson JW, Whyte GP, McConnell AK, et al. Impact of changes in the IOC-MC asthma criteria: a British perspective. Thorax 2005;60:629-32.

5 Langdeau JB, Boulet LP. Is asthma over- or underdiagnosed in athletes? Respir Med 2003;97:109-14.

6 Goubault C, Perault MC, Leleu E, et al. Effects of inhaled salbutamol in exercising non-asthmatic athletes. Thorax 2001;56:675-9.

7 Morton AR, Joyce K, Papalia SM, et al. Is salmeterol ergogenic? Clin J Sport Med 1996;6:220-5.

8 Carlsen KH, Hem E, Stensrud T, et al. Can asthma treatment in sports be doping? The effect of the rapid onset, long-acting inhaled beta 2 -agonist formoterol upon endurance performance in healthy well-trained athletes. Respir Med 2001;95:571-6.

9 Anderson, Fitch K, Perry C, et al. Responses to bronchial challenge submitted for approval to use inhaled $\beta_{2}$-agonists before an event at the 2002 winter Olympics. J Allergy Clin Immunol 2003;111:45-50.

10 Medical Commission of the International Olympic Committee. IOC's medical code. Lausanne: International Olympic Committee, 2002.

11 Rytila P, Metso T, Heikkinen K, et al. Airway inflammation in patients with symptoms suggesting asthma but with normal lung function. Eur Respir J 2000;16:824-30.

12 Helenius I, Lumme A, Ounap J, et al. No effect of montelukast on asthma-like symptoms in elite ice hockey players. Allergy 2004;59:39-44

13 Boulet LP. Physiopathology of airway hyperresponsiveness. Curr Allergy Asthma Rep 2003;3:166-71

14 Hemingson HB, Davis BE, Cockcroft DW. Seasonal fluctuations in airway responsiveness in elite endurance athletes. Can Respir J 2004; 11:399-401.

15 Boulet LP. Asymptomatic airway hyperresponsiveness: a curiosity or an 
opportunity to prevent asthma? Am J Respir Crit Care Med 2003:167:371-8.

16 Rundell K, Im J, Mayers L, et al. Self-reported symptoms and exercise-induced asthma in the elite athlete. Med Sci Sports Exerc 2001;33:208-13.

17 LindenSmith J, Morrison D, Deveau C, et al. Overdiagnosis of asthma in the community. Can Respir J 2004;11:111-6.
18 Turcotte H, Langdeau JB, Bowie DM, et al. Are questionnaires on respiratory symptoms reliable predictors of airway hyperresponsiveness in athletes and sedentary subjects? J Asthma athletes and sedenta

19 Boulet LP, Becker A, Berube D, et al. Canadian Asthma Consensus Report, 1999. Canadian Asthma Consensus Group. Can Med Assoc J 1999;161:S1.
20 British Thoracic Society/Scottish Intercollegiate Guidelines Network. British guideline on the management of asthma. Thorax 2003;58(Suppl 1):i1-94.

21 Alaranta A, Alaranta H, Palmu P, et al Asthma medication in Finnish olympic athletes: no signs of inhaled beta2-agonist overuse. Med Sci Sports Exerc 2004;36:919-24.

\section{Surfactant and lung inflammation}

\section{K B M Reid, H Clark, N Palaniyar}

\section{SP-A and SP-D, either on their own or in combination with existing surfactant therapy, may have a role in the treatment of lung inflammation}

$\mathrm{T}$ he thin alveolar lining consists of a single layer of epithelial cells and an overlay of an oily substance, the pulmonary surfactant, which contains surfactant proteins (SPs) $(10 \% \mathrm{w} / \mathrm{w})$ and lipids $(90 \% \mathrm{w} / \mathrm{w})$. In addition to the well established ability of the surfactant system to reduce alveolar surface tension and thereby prevent collapse of the alveoli on expiration, it is also involved in the very efficient removal of microbes and their debris, ${ }^{1-3}$ dying epithelial cells, and phagocytes. ${ }^{4}$ The therapeutic use of exogenous surfactant is well established and has been shown to be effective in the treatment of premature infants with respiratory distress syndrome. The surfactant preparations normally used are natural surfactants of porcine (Curosurf) or bovine (Alveolfact, Survanta) origin, or synthetic protein free preparations. Surfactant preparations derived from natural sources contain the hydrophobic peptides SP-B and SP-C but none-or very low levels-of the much larger hydrophilic surfactant proteins SP-A and SP-D which are lost during the extraction procedure. Although surfactant lipids may reduce lung inflammation, recent studies suggest that these hydrophilic proteins are the major antiinflammatory components of pulmonary surfactant.

EXISTING SURFACTANT THERAPY Over the past 10 years it has become recognised that SP-A and SP-D-members of the innate immune collectin family of proteins which are secreted by type II alveolar epithelial cells-play important host defence and immunomodulatory functions in the surfactant system. ${ }^{5}{ }^{6} \mathrm{SP}-\mathrm{A}(\sim 90 \% \mathrm{w} / \mathrm{w}$ of SPs) and
SP-D ( $\sim 3 \% \mathrm{w} / \mathrm{w}$ of SPs) are the major surfactant proteins and are involved in maintaining an infection-free and inflammation-free lung. ${ }^{78}$ During acute lung infections these innate immune molecules can kill ${ }^{9}$ and/or opsonise and enhance the phagocytosis of microbes by freshly recruited phagocytes. They also bind to apoptotic polymorphonuclear leucocytes and alveolar macrophages and enhance their clearance by healthy resident macrophages. ${ }^{10}{ }^{11}$ It has recently been suggested that surfactant therapy may also be beneficial in cases of adult acute respiratory distress syndrome, since clinical trials in patients with respiratory failure due to pneumonia showed improved oxygenation and no serious side effects following surfactant therapy. ${ }^{12}{ }^{13}$ This is consistent with in vitro studies showing that surfactant does not interfere significantly with the phagocytic capacity of polymorphonuclear neutrophils stimulated by bacteria opsonised with specific IgG antibody. ${ }^{13}$ If surfactant preparations are to be used more widely, it may also be worth considering administering SP-A and/or SP-D to the same groups of patients.

\section{Surfactant proteins SP-A and SP-D}

These two human surfactant proteins are extremely well characterised, both having a typical collectin structure composed of polypeptide chains containing a short interchain disulfide bond forming $\mathrm{N}$-terminal domain, a collagenlike region with Gly-X-Y repeats (where $\mathrm{X}$ is any amino acid and $\mathrm{Y}$ is often hydroxyproline or hydroxylysine), an $\alpha$ helical hydrophobic neck region, and a C-terminal globular carbohydrate recognition domain (CRD) ${ }^{14-16}$ Three of these polypeptides form a trimeric subunit which assembles to form higher order structures. The oligomeric assembly of SP-D" ${ }^{16} 17$ resembles that of an " $X$ " (4 subunits) or "asterisk" (>12 subunits) whereas the SP-A, by the association of up to six trimeric subunits, appears as a "bouquet of flowers". ${ }^{5}{ }^{17-19}$ Although the trimeric subunits of the collectins have only limited affinity ( $\mathrm{mM}$ ) for carbohydrate targets on their own, their oligomeric assembly provides a high avidity so that the oligomeric proteins bind to ligands selectively and with high affinity (pM). One reason that SP-A has not been included in surfactant preparations was the concern that humans may raise antibodies to animal surfactant proteins. However, recently it has become possible to generate smaller recombinant fragments of these lung collectins which retain their activity without being immunogenic (in mice).

In the lung, SP-A and SP-D opsonise microbes, allergens, and other foreign bodies to varying degrees and signal their clearance by resident alveolar macrophages and other leucocytes. ${ }^{6}$ These proteins also bind some of the well known inflammation causing ligands from bacterial cell walls-such as lipopolysaccharide, peptidoglycans and lipoteichoic acid-primarily via hexose sugars. ${ }^{5}$ Recent studies show that SP-A and SP-D recognise leucinerich repeat (LLR) containing proteins such as Toll-like receptor 2 (TLR-2) ${ }^{20}$ and decorin, ${ }^{21}$ respectively. Binding of SP-A to TLR-2 inhibits the peptidoglycan induced inflammatory signal produced by phagocytes, ${ }^{20}$ which explains some of the possible mechanisms involved in the anti-inflammatory property of collectins. SP-A may also bind to Clq and dampen the complement activation and, hence, could reduce lung inflammation. ${ }^{22}$

The characterisation of the natural ligands and regulatory proteins in the lungs involved-together with SP-A and SP-D-in the identification and clearance of apoptotic cells is presently a very active area of research. ${ }^{23-26}$ The likely critical involvement of SP-D in the modulation of lung homeostasis is indicated by the examination of the lungs of gene targeted mice deficient in SP-D, which show a low grade macrophage mediated lung inflammation and 
ultimately exhibit structural alterations such as hypertrophy and hyperplasia of type II cells, a diminished number of alveoli, increased alveolar size and decreased alveolar surface area, consistent with the definition of pulmonary emphysema. ${ }^{27}$ This is accompanied by an intra-alveolar accumulation of alveolar macrophages, many of which are enlarged and foamy. Surfactant homeostasis is disturbed, indicated by the presence of giant lamellar bodies in some type II cells and the development of alveolar lipoproteinosis. ${ }^{78}$ In addition to the increased intra-alveolar surfactant pool, stereological analysis has revealed the existence of an increased intracellular surfactant pool due to an increase in the number and size of lamellar bodies per type II cell and the number of type II cells per lung. ${ }^{7}$

\section{ANIMAL MODEL OF SP-D DEFICIENCY}

SP-D deficiency brings about a chronic inflammatory state characterised by increased levels of reactive oxygen species as well as a raised expression of matrix metalloproteinases, which could be responsible for the pulmonary remodelling process resulting in alveolar destruction consistent with these structural findings. ${ }^{10}{ }^{28}$ Moreover, a considerable number of apoptotic and necrotic alveolar macrophages was observed in the bronchoalveolar lavage (BAL) fluid, providing evidence that a delayed clearance of dead cells may be involved in the chronic inflammatory state of SP-D deficiency. Previous reports had identified a role for SP-A and SP-D in the phagocytosis of apoptotic and necrotic cells in vitro, ${ }^{29}$ though SP-D appeared to be more important for this function than other collectins in vivo. ${ }^{10}{ }^{30}$ This essential role of SP-D has been emphasised by experiments involving the intranasal administration of a truncated $60 \mathrm{kDa}$ fragment of human SP-D (rfhSP-D) to SP-D knock-out mice, which resulted in a significant reduction in the number of apoptotic and necrotic alveolar macrophages in BAL fluid and a decrease in inflammatory mediators and intra-alveolar lipid accumulation. ${ }^{10} 30$ Application of rfhSP-D to mice suffering from allergic asthma also showed a dampening of the allergic response due to allergen inhalation with a modification of cytokine levels and a decrease in airway hyperresponsiveness on allergen challenge. ${ }^{31}{ }^{32}$ Allergen challenge upregulates collectin (particularly SP-D) expression in the lungs, both in allergic mice $^{33}$ and patients. ${ }^{34}$ The allergic inflammation may directly be modulated by collectins altering cytokine production and macrophage functions. ${ }^{36}$

\section{INTERACTION OF SP-A AND SP-D WITH DNA}

A recent study has shown that SP-A and SP-D can bind to DNA, ${ }^{37}$ which may be of physiological significance in terms of control of inflammation since apoptotic cell death results in the fragmentation of DNA and its subsequent display on the surface as blebs. ${ }^{4}$ Inefficient removal of apoptotic cells leads to disintegration of their contents and the formation of necrotic cells. ${ }^{4}$ These leaky cells eventually release their intracellular components and many of these components elicit tissue inflammation generation. Furthermore, certain pulmonary pathogens such as Pseudomonas aeruginosa actively secrete DNA onto the extracellular matrix to form active biofilm and subsequently to establish chronic infection. ${ }^{3}$ Patients with cystic fibrosis suffer from (and may die of) chronic microbial infection, lung inflammation, and accumulation of apoptotic and necrotic neutrophils and their cell contents such as DNA. These patients show a deficiency in levels of SP-A and SP-D, ${ }^{38}$ and the concentrations of these collections are inversely related to inflammation in early cystic fibrosis. ${ }^{39}$ Removal of dying cells and their components (including DNA) is therefore essential for maintaining inflammation-free tissues and preventing autoimmune diseases. ${ }^{4}$ Although the multiple pathways and proteins involved in the apoptotic process have been studied in great detail, clearance of these cell debris and autoantigens is poorly understood. Free DNA and RNA-as well as the DNA present on apoptotic cells-constitute a novel class of ligands for the collectins SP-A, SP-D and MBL, ${ }^{37}$ and it has been found that collectins, particularly SP-D, effectively enhance the uptake of DNA and DNA containing beads by macrophages in vitro, and the absence of SP-D in vivo leads to increased anti-DNA autoantibody generation.

\section{CONCLUSIONS}

Thus there is increasing support for the view that recombinant forms of SP-A or SP-D, either on their own or with existing surfactant therapy, may be worth considering as therapeutic agents in the treatment of lung inflammation associated with injury, allergy, or infection. However, the intact collectin proteins are very large (around $600 \mathrm{kDa}$ ), there are two functional SP-A genes, and several allelic variants of both proteins (which may show significantly different structural and functional properties). The preparation of functionally active recombinant forms of the whole SP-A and SP-D proteins is therefore complicated and their efficient delivery to the lungs may be difficult and expensive. A recombinant fragment (although still $60 \mathrm{kDa}$ in size) of SP-D, which has been shown to retain many of the anti-inflammatory properties of the whole molecule, may offer a first step in the use of the protective properties of these proteins of innate immunity in the treatment of lung inflammation.

Thorax 2005;60:620-622.

doi: $10.1136 /$ thx.2004.036699

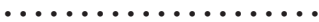

Authors' affiliations

K B M Reid, H Clark, MRC Immunochemistry Unit, Department of Biochemistry, University of Oxford, Oxford OXI ODQ, UK

N Palaniyar, Lung Biology Research Program, Hospital for Sick Children Research Institute, Toronto, Ontario 5G 1X8, Canada

Correspondence to: Professor K B M Reid, MRC Immunochemistry Unit, Department of

Biochemistry, University of Oxford, South Parks Road, Oxford OXI ODQ, UK; kenneth.reid@

bioch.ox.ac.uk

\section{REFERENCES}

1 Sparwasser T, Miethke T, Lipford G, et al. Bacterial DNA causes septic shock. Nature 1997;386:336-7.

2 Krieg AM, Yi AK, Matson S, et al. CpG motifs in bacterial DNA trigger direct B-cell activation. Nature 1995;374:546-8.

3 Whitchurch CB, Tolker-Nielsen T, Ragas PC, et al. Extracellular DNA required for bacterial biofilm formation. Science 2002;295: 1487.

4 Savill J, Dransfield I, Gregory C, et al. Haslett. A blast from the past: clearance of apoptotic cells regulates immune responses. Nat Rev Immunol 2002;2:965-8

5 Crouch E, Wright JR. Surfactant proteins A and D and pulmonary host defense. Annu Rev Physiol 2001;63:521-54.

6 McCormack FX, Whitsett JA. The pulmonary collectins, SP-A and SP-D, orchestrate innate immunity in the lung. $J$ Clin Invest 2002; 109:707-12.

7 Botas C, Poulain F, Akiyama J, et al. Altered surfactant homeostasis and alveolar type II cell morphology in mice lacking surfactant protein $D$. Proc Natl Acad Sci USA 1998;95:11869-74.

8 Korfhagen TR, Sheftelyevich V, Burhans MS, et al. Surfactant protein-D regulates surfactant phospholipid homeostasis in vivo. J Biol Chem 1998;273:28438-43.

9 Wu H, Kuzmenko A, Wan S, et al. Surfactant proteins $A$ and $D$ inhibit the growth of Gram-negative bacteria by increasing membrane permeability. $J$ Clin Invest 2003; 111:1589-602

10 Clark H, Palaniyar N, Strong P, et al. Surfactant protein $D$ reduces alveolar macrophage apoptosis in vivo. J Immunol 2002;169:2892-9.

11 Vandivier RW, Ogden CA, Fadok VA, et al. Role of surfactant proteins $A, D$, and $\mathrm{Clq}$ in the clearance of apoptotic cells in vivo and in vitro: calreticulin and CD91 as a common collectin receptor complex. J Immunol 2002;169:3978-86.

12 Herting E, Molller O, Schiffmann JH, et al. Surfactant improves oxygenation in infants and children with pneumonia and acute respiratory distress syndrome. Acta Paediatr 2002;91:1174-8.

13 Rauprich P, Walter G, Jarstrand C, et al. Influence of modified natural and synthetic surfactant preparations on bacterial killing by polymorphonuclear leucocytes. Immunobiology 2004;209:609-17

14 Hakansson K, Reid KBM. Collectin structure: a review. Protein Sci 2000;9:1607-17. 
15 Persson A, Chang D, Crouch E. Surfactant protein $D$ is a divalent cation dependent carbohydratebinding protein. J Biol Chem 1990;265:5755-60.

16 Crouch E, Chang D, Rust K, et al. Recombinant pulmonary surfactant protein $D$. Post-translational modification and molecular assembly. J Biol Chem 1994:269:15808-13.

17 Lu J, Wiedemann H, Timpl R, et al. Similarity in structure between $\mathrm{Clq}$ and the collectins as judged by electron microscopy. Behring Inst Mitt 1993;93:6-16.

18 Palaniyar N, Ridsdale RA, Holterman CE, et al. Structural changes of surfactant protein $A$ induced by cations reorient the protein on lipid bilayers. J Struct Biol 1998; 122:297-310.

19 Palaniyar N, Ikegami M, Korfhagen T, et al. Domains of surfactant protein $A$ that affect protein oligomerization, lipid structure and surface tension. Comp Biochem Physiol A Mol Integr Physiol 2001;129:109-15.

20 Murakami S, Iwaki D, Mitsuzawa $\mathrm{H}$, et al Surfactant protein A inhibits peptidoglycaninduced tumor necrosis factor-alpha secretion in U937 cells and alveolar macrophages by direct interaction with toll-like receptor 2. J Biol Chem 2002;277:6830-5

21 Nadesalingam J, Bernal AL, Dodds AW, et al. Identification and characterization of a novel interaction between pulmonary surfactant protein D and decorin. J Biol Chem 2003;278:25678-81.

22 Wright JR. Immunoregulatory functions of surfactant proteins. Nat Rev Immunol 2005:5:58-68

23 Gardai SJ, Xiao Y-Q, Dickinson M, et al. By binding SIRP $\alpha$ or calreticulin/CD91, lung collectins act as dual function surveillance molecules to suppress or enhance inflammation. Cell 2003:115:13-23.
24 Anderson HA, Maylock CA, Williams JA, et al. Serum-derived protein $\mathrm{S}$ binds to phosphatidylserine and stimulates the phagocytosis of apoptotic cells. Nat Immunol 2003;4:87-8

25 Hanayama R, Tanaka M, Miwa K, et al. dentification of a factor that links apoptotic cells to phagocytes. Nature 2002;417:182-3.

26 Ezekowitz RA. Local opsonization for apoptosis? Nat Immunol 2002;3:510-2.

27 Wert SE, Yoshida M, LeVine AM, et al. Increased metalloproteinase activity, oxidant production, and emphysema in surfactant protein D geneinactivated mice. Proc Natl Acad Sci USA 2000;97:5972-7

28 Yoshida M, Korfhagen TR, Whitsett JA. Surfactant protein $D$ regulates NF- $\kappa B$ and matrix metalloproteinase production in alveolar macrophages via oxidant-sensitive pathways. J Immunol 2001;166:7514-9.

29 Schagat TL, Wofford JA, Wright JR. Surfactant protein A enhances alveolar macrophage phagocytosis of apoptotic neutrophils. J Immunol 2001; 166:2727-33

30 Clark HW, Palaniyar N, Hawgood S, et al. A recombinant fragment of human surfactant protein $D$ reduces of alveolar macrophages apoptosis and pro-inflammatory cytokines in mice developing pulmonary emphysema. Ann NY Acad Sci 2003;1010:113-6.

31 Strong $P$, Townsend P, Mackay R, et al. A recombinant fragment of human SP-D reduces allergic responses in mice sensitized to house dust mite allergens. Clin Exp Immunol 2003;134:181-7.

32 Strong P, Reid KBM, Clark HW. Intranasal delivery of a truncated recombinant human SP-D is effective at down-regulating allergic hypersensitivity in mice sensitized to allergens of
Aspergillus fumigatus. Clin Exp Immunol 2002; 130:19-24.

33 Haczku A, Vass G, Kierstein S. Surfactant protein D and asthma. Clin Exp Allergy 2004;34:1815-21.

34 Hohlfeld JM, Erpenbeck VJ, Krug N. Surfactant proteins SP-A and SP-D as modulators of the allergic inflammation in asthma. Pathobiology 2002;70:287-92.

35 Koopmans JG, van der Zee JS, Krop EJ, et al. Serum surfactant protein $D$ is elevated in allergic patients. Clin Exp Allergy 2004:34:1827-31.

36 Takeda K, Miyahara N, Rha YH, et al. Surfactant protein $D$ regulates airway function and allergic inflammation through modulation of macrophage function. Am J Respir Crit Care Med 2003:168:783-9.

37 Palaniyar N, Nadesalingam J, Clark H, et al. Nucleic acid is a novel ligand for innate, immune pattern recognition collectins - surfactant protein A and mannose-binding lectin. $J$ Biol Chem 2003;279:32728-36.

38 Postle AD, Mander A, Reid KB, et al. Deficient hydrophilic lung surfactant proteins $A$ and $D$ with normal surfactant phospholipid molecular species in cystic fibrosis. Am J Respir Cell Mol Bio 1999:20:90-8.

39 Noah TL, Murphy PC, Alink JJ, et al. Bronchoalveolar lavage fluid surfactan protein-A and surfactant protein-D are inversely related to inflammation in early cystic fibrosis. Am J Respir Crit Care Med 2003; 168:685-91.

40 Palaniyar N, Clark H, Nadesalingam J, et al. Surfactant protein D binds genomic DNA and apoptotic cells and enhances their clearance in vivo. Ann NY Acad Sci 2003;1010:471-5.

\section{LUNG ALERT}

\section{$\mathrm{N}$-Acetylcysteine and disease progression in COPD}

$\Delta$ Decramer M, Rutten-van Mölken M, Dekhuijzen PR, et al. Effects of N-acetylcysteine on outcomes in chronic obstructive pulmonary disease (Bronchitis Randomized on NAC Cost-Utility Study, BRONCUS): a randomized placebo-controlled trial. Lancet 2005;365:1552-60

$\mathrm{t}$ is known that oxidative stress plays an important role in the pathogenesis of chronic obstructive pulmonary disease (COPD). In this study the anti-oxidant $\mathrm{N}$-acetylcysteine

(NAC) was used to assess whether this drug could reduce the rate of lung function decline, reduce the yearly exacerbation rate, or improve clinical outcomes. 523 patients were randomised to receive either $600 \mathrm{mg}$ NAC daily or placebo over a 3 year period. Forced expiratory volume in 1 second $\left(\mathrm{FEV}_{1}\right)$ and yearly exacerbation rates were monitored.

No significant differences were found in the rate of $\mathrm{FEV}_{1}$ decline $(54 \mathrm{ml} /$ year NAC $v$ $47 \mathrm{ml} /$ year placebo) or number of exacerbations per year ( $1.25 \mathrm{NAC} v 1.29$ placebo) between the two groups. Further subgroup analysis did suggest that there may be a benefit on the exacerbation rate in those patients not treated with inhaled steroids.

This study has shown that NAC when given at this dose does not reduce the rate of decline in lung function or reduce exacerbation rate in patients with COPD.

Specialist Registrar, Newham University Hospital, London, UK; karnan@doctors.org.uk 